\title{
Effect of sulodexide in patients with non-proliferative diabetic retinopathy: diabetic retinopathy sulodexide study (DRESS)
}

\author{
Ji Hun Song • Hee Seung Chin • Oh Woong Kwon • \\ Su Jin Lim • Ha Kyoung Kim • for the DRESS Research Group
}

Received: 26 April 2014 /Revised: 1 July 2014 / Accepted: 8 July 2014 /Published online: 12 August 2014

(C) The Author(s) 2014. This article is published with open access at Springerlink.com

\begin{abstract}
Purpose To evaluate the effectiveness of sulodexide for the treatment of hard exudates (HE) in non-proliferative diabetic retinopathy (NPDR).

Methods This was a randomized, placebo-controlled, multicenter trial involving 130 patients ( 65 for each group) who had mild-to-moderate NPDR with macular HE. Participants were given a daily dose of either $50 \mathrm{mg}$ sulodexide or a matching dose of placebo orally for 12 months. Main outcome measure was an improvement in HE defined as a decrease in severity by at least two grades on a 10-grade severity scale. This was evaluated by fundus photography over 12-month period. Results The sulodexide group showed significantly greater improvement in HE severity than that shown by the placebo group ( $39.0 \%$ vs. $19.3 \%$; chi square, $P=0.005)$. Logistic regression analysis yielded an odds ratio of $2.790(95 \%$
\end{abstract}

This article was presented in part as a poster at the 2011 Annual Meeting of the American Academy of Ophthalmology (PO498), October 2011, Orlando, FL, USA

The authors have full control of all primary data and agree to allow Graefe's Archive for Clinical and Experimental Ophthalmology to review data upon request.

\section{J. H. Song}

Department of Ophthalmology, Ajou University School of Medicine, Suwon, Korea

\section{H. S. Chin}

Department of Ophthalmology, Inha University School of Medicine, Incheon, Korea

O. W. Kwon · S. J. Lim

The Retina Center, Nune Eye Hospital, Seoul, Korea

H. K. Kim $(\bowtie)$

Department of Ophthalmology, Kangnam Sacred Heart Hospital,

College of Medicine, Hallym University, \#948-1 Daerim 1-dong,

Yeongdeungpo-gu, Seoul 150-950, Korea

e-mail: 5193eye@naver.com confidence interval, 1.155-6.743; $P=0.023$ ) for the effect of treatment once adjustments were made for demographic, prognostic and disease confounders. Intention to treat and per-protocol analysis yielded similar results. Sulodexide's safety was comparable to that of the placebo.

Conclusions Oral sulodexide therapy over 12 months improved macular HE in patients with mild-to-moderate NPDR, without leading to detectable adverse events. The study protocol was registered on clinicaltrial.gov under identifier NCT01295775.

Keywords Diabetic retinopathy $\cdot$ Hard exudates . Randomized controlled trial $\cdot$ Sulodexide

\section{Introduction}

Diabetic retinopathy is the leading cause of new onset blindness among the working-age group in industrialized countries, affecting from 2 to $5 \%$ of the entire population [1]. The first microscopic changes are thickening of the retinal capillary basement membrane and degeneration of pericytes, both of which compromise the integrity of the capillary wall, followed by pericyte loss. Collagen progressively replaces the glycosaminoglycans (GAGs) of the basal membrane, leading to modifications in vascular permeability due to altered anionic charge. These changes eventually result in the clinical appearance of vascular leakage from the retinal capillaries followed by microaneurysms. If vascular leakage persists, serum proteins and lipids deposit in the retina and form hard exudates (HE).

The substitution of GAGs by collagen leads to a basal membrane thickening also in the kidney. As in the retina, these changes in permeability of the renal glomeruli induce the selective loss of proteins, clinically detected as albuminuria [2]. It has been suggested that altered GAG metabolism in 
diabetes patients could be a common pathogenic factor in diabetic vascular disease [3]. Evidence that both diabetic retinopathy and nephropathy have a common underlying pathogenesis (the depletion of GAGs from the basement membrane) is supported by the findings of the Wisconsin Epidemiologic Study of Diabetic Retinopathy in which micro-albuminuria was reported to be cross-sectionally associated with retinopathy in diabetes patients [4]. Since current anti-hyperglycemic therapy cannot fully prevent the complications associated with diabetes, it is imperative to find new drugs that can slow or reverse the vascular microabnormalities that ensue.

Sulodexide (Vessel Due $F^{\circledR}$, Aju Pharm, Seoul, South Korea, under license from Alfa Wassermann, Bologna, Italy) is a GAG that consists of heparin and dermatan sulfate, and is available for oral administration [5]. It has a high trophism for the vessel wall $[6,7]$. Clinical studies have already shown its efficacy in decreasing micro- and macro-albuminuria in diabetes patients, thus suggesting that the partial restoration of glomerular GAG content might slow the progression of nephropathy [8-13]. Moreover, preliminary observations on the use of sulodexide in patients with diabetic retinopathy was a significant reduction in HE, thus indicating a potential benefit of this GAG at the retinal capillary level [14, 15].

On the basis of these pathophysiological considerations and experimental findings, we decided to evaluate the effects of sulodexide on diabetic retinopathy in a double-masked, randomized, placebo-controlled, multicenter trial: the Diabetic Retinopathy Sulodexide Study (DRESS). In this phase-2 study, we aimed to assess the effectiveness of sulodexide for the treatment of $\mathrm{HE}$ in non-proliferative diabetic retinopathy (NPDR), in patients with type 1 and type 2 diabetes mellitus (DM).

\section{Methods}

\section{Study design}

This was a double-masked, randomized, controlled, multicenter study consisting of 130 patients ( 65 for each treatment arm) with mild-to-moderate NPDR. Table 1 shows the selection criteria for the study population. At baseline (T0), ocular lesions were graded using color fundus photography and fluorescein angiography (FA). The photographs and FA images were subsequently sent to a review committee comprising off-site assessors (JH Song, SJ Lim, and HS Chin), who were unaware of the initial investigators' assessment. This committee was nominated to confirm the quality of the images and the grade of the lesions. After this validation process, eligible patients were blindly allocated into the following two groups using a computer-generated list: test (sulodexide) and control (placebo) groups. Two daily oral dose of sulodexide $25 \mathrm{mg}$ or the matching placebo were administered to each patient, one capsule in the morning and one capsule in the evening, for $360 \pm 7$ days. The selected dosage regimen for this study was based on previously published clinical trial data on sulodexide $[7,9,11,12,16]$. Patients were then evaluated at 3 (T3), 6 (T6), 9 (T9), and 12 months (T12) with a 1-week window allowed around the follow-up times. This study was approved by the institutional review board (IRB) and/or the ethics committee of each participating center, and conducted in accordance with the Declaration of Helsinki and the guidelines on good clinical practice. All participants signed the written informed consent in the form approved by the relevant IRB. The study protocol was registered on clinicaltrial.gov under identifier NCT01295775.

\section{Ophthalmic evaluation}

A comprehensive ophthalmic examination was performed during every visit, including assessment of best-corrected visual acuity (BCVA) using the Early Treatment Diabetic Retinopathy Study (ETDRS) protocol; intraocular pressure (IOP) measurement; slit lamp biomicroscopy; and indirect ophthalmoscopy. Fundus photography and a contrast sensitivity test (CST) using the Mars Letter CST (Mars Perceptrix, Chappaqua, NY, USA), were performed during every visit. Optical coherence tomography (OCT) and FA were performed at T0, T6, and T12. Macular thickness was measured by OCT (Stratus OCT, Carl Zeiss Meditec, Dublin, CA, USA), and changes in the mean 1-mm central foveal thickness (CFT) served to evaluate changes in macular edema.

\section{Efficacy end-points}

The primary efficacy endpoint of this study was an improvement of HE, defined as a decrease in HE by at least two categories of severity. Fundus photography was performed on fields F1 and F2 (ETDRS Standard), and the HE were graded according to the specific grading system of this study which uses an extension of the Airlie House classification, while FA was performed on seven standard fields (ETDRS Standard) and graded according to ETDRS [17, 18]. The grading of HE was based on the area of retina involved and the amount of HE observed, using ETDRS standard photographs 3 and 4 for comparison, as follows (Fig. 1);

\section{Grading of hard exudates}

Grade 1 Questionable HE

Grade 2 Definite HE; fewer than those in standard photograph 3

Grade 3 HE; as many as those in standard photograph 3

Grade 4 HE; more than those in standard photograph 3, but fewer than those in standard photograph 4 
Table 1 Selection of study population

\begin{tabular}{ll}
\hline Inclusion criteria & Exclusion criteria
\end{tabular}

Patients aged over 18 years with type 1 or type 2 DM

Diabetes under good control with drugs for at least 6 months (HbA1c $<9 \%$ [75 $\mathrm{mmol} / \mathrm{mol}])$

CFT $\leq 300$ um of retina by OCT

Snellen visual acuity $\geq 0.4(20 / 50)$

Mild-to-moderate NPDR assessed by fundus photography and FA according to Airlie House Classification and ETDRS:

(i) the presence of hard exudates within grade 2 and 5

(ii) at least one of the following lesions: vascular leakages, microaneuryms, hemorrhages, IRMA

$\mathrm{DBP} \leq 90 \mathrm{mmHg}$ and $\mathrm{SBP} \leq 130 \mathrm{mmHg}$ with or without medication

Controlled arterial blood pressure for the last 6 months
NPDR which is being treated with laser therapy or should be treated with laser therapy before the end of the study

Laser therapy or intravitreal injection (anti-VEGF, steroid) within 3 months from enrollment

Concomitant retinal disease due to causes other than diabetic microangiopathy

Concomitant therapy

(i) antihypertensive treatment, unless administered at stable dosage for at least 6 months before the start of the study

(ii) ACE inhibitor/ARB therapy, unless administered at stable dosage for at least 6 months before the start of the study

(iii) warfarin therapy

(iv) hemorrheological, vasoactive drugs and antithrombotics except acetylsalicylic acid at stable dosage

Severe liver impairment (CHILD C)

Severe renal insufficiency (creatinine $>2.2 \mathrm{mg} / \mathrm{dl}$ )

Severe cardiac insufficiency (NYHA - New York Heart Association classes $3-4)$

Clinical history of diathesis and haemorrhagic disease

Individual hypersensitivity toward the product, heparin, low molecular weight heparin, or heparin-like products

Intended or ascertained pregnancy or lactation

Participation in a trial within the past 6 months

Surgery or trauma within the past 6 months

Planned surgical intervention within 6 months from enrolment

$\mathrm{ACE}=$ angiotensin-converting enzyime, $\mathrm{ARB}=$ angiotensin-receptor blocker, $\mathrm{CFT}=$ central foveal thickness, $\mathrm{DBP}=$ diastolic blood pressure, $\mathrm{DM}=$ diabetes mellitus, ETDRS = early treatment diabetic retinopathy study, FA = fluorescein angiography, IRMA = intraretinal microvascular abnormalities, $\mathrm{NPDR}=$ non-proliferative diabetic retinopathy, $\mathrm{OCT}=$ optical coherence tomography, $\mathrm{SBP}=$ systolic blood pressure, $\mathrm{VEGF}=$ vascular endothelial growth factor

Grade 5 HE; more than or as many as those in standard photograph 4

Since the grade 4 fundus photographs included too wide a range, it was divided into grade $4 \mathrm{a}$ and $4 \mathrm{~b}$, which in turn were divided into "-", " 0 ", and "+" grades in order to measure adequately the changes in HE.

Grade 4a- Very mild deposition of scattered HE but more than those in standard photograph 3

Grade 4a Mild deposition of scattered HE
Grade 4a+ Mild-to-moderate deposition of scattered HE

Grade 4b- Moderate deposition of HE with any circinate form

Grade 4b Moderate-to-severe deposition of HE with any circinate form

Grade $4 b+$ Severe deposition of HE with any circinate form, but fewer than those in standard photograph 4

Thus, the fundus photographs yielded a grading of HE that spanned 10 grades overall $(1,2,3,4 a-, 4 a, 4 a+, 4 b-, 4 b, 4 b+, 5)$ (Fig. 2). Fundus photographs were graded in a masked fashion

Fig. 1 The early treatment diabetic retinopathy study (ETDRS) standard photographs 3 (a) and 4 (b). From the Early Treatment Diabetic Retinopathy Study Research Group (1991); Grading diabetic retinopathy from stereoscopic color fundus photographs - an extension of the modified Airlie House classification. Ophthalmology 98:786806. Reprinted courtesy of Elsevier
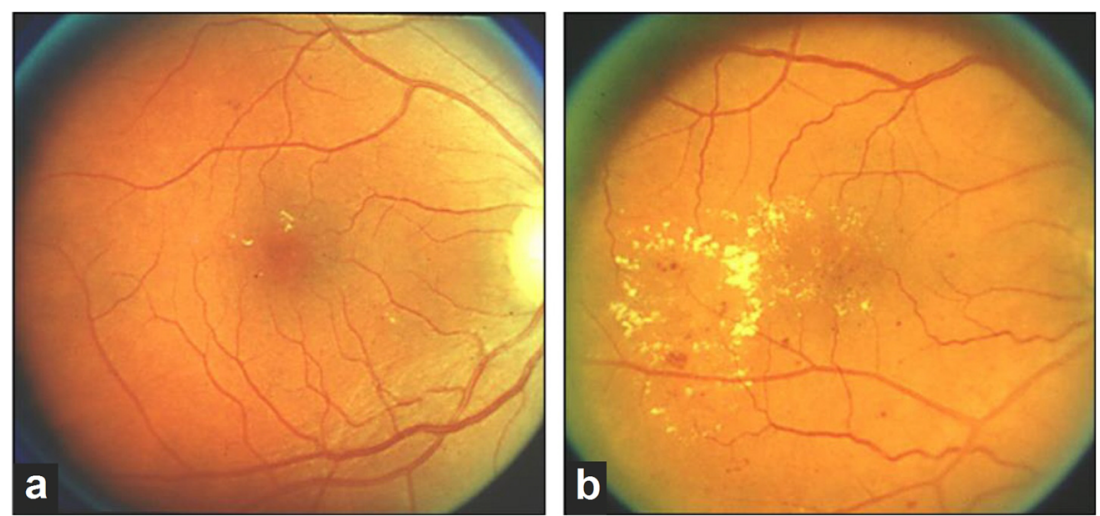

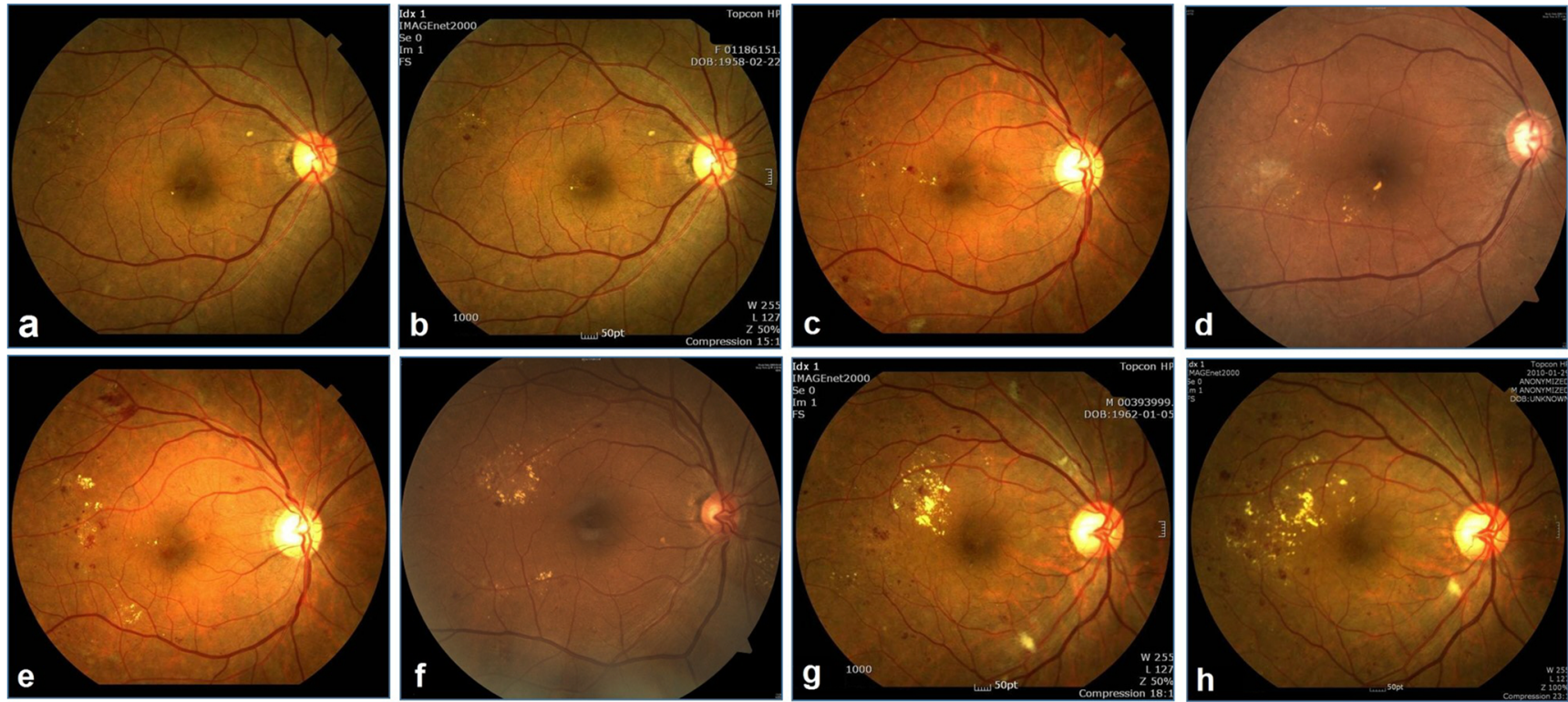

Fig. 2 Typical examples of fundus photographs in each grade. a Grade 2. b Grade 3. c Grade 4a-. d Grade 4a. e Grade 4a+. f Grade 4b-. g Grade 4b. h Grade 4b+

by two independent graders (J. H. S. and S. J. L.) and adjusted by a third grader (H. S. C.) in cases of disagreement.

The secondary efficacy endpoints encompassed improvements in vascular leakage; microaneurysms; hemorrhages; intraretinal microvascular abnormalities at FA, BCVA, IOP and CFT as detected by OCT, and CST.

\section{Safety endpoints}

Vital signs were monitored during each visit while hematology and clinical chemistry were examined at $\mathrm{T} 0$ and $\mathrm{T} 12$ visits. The laboratory safety tests included tests for the following: red blood cell count (RBC); white blood cell count (WBC) with differential count; platelets; hematocrit (Hct); hemoglobin $(\mathrm{Hb})$; erythrocyte sedimentation rate (ESR); blood creatinine level; aspartate aminotransferase (AST) level; alanine aminotransferase (ALT) level; gamma glutamyltransferase $(\gamma \mathrm{GT})$ level; blood fibrinogen level; activated partial thromboplastin time (aPTT); and lipid panel. We also monitored fasting blood glucose and glycosylated hemoglobin ( $\mathrm{HbAlc}$ ) during each visit. Lastly, possible adverse effects of treatment were monitored by investigators who questioned the patient during each visit and on the final day of assessment.

\section{Study populations}

Figure 3 reports patients' dispositions. The primary test population was the intention-to-treat (ITT) population, which included all patients who were randomized to treatment, received the medication they had been randomized to, and had both valid baseline and 12-month fundus photography. The secondary test population was the per-protocol (PP) population, which included all patients of the ITT population who, in addition to this, complied with all the inclusion and exclusion criteria and took at least $80 \%$ of the planned treatment doses. The safety population included all the 127 patients who participated in the trial, who received the medication they had been randomized to, and who were seen at least once by the attending physician (Fig. 3).

\section{Statistical methods}

The primary variable was an improvement of HE in NPDR that was defined in this study as a decrease in HE by at least

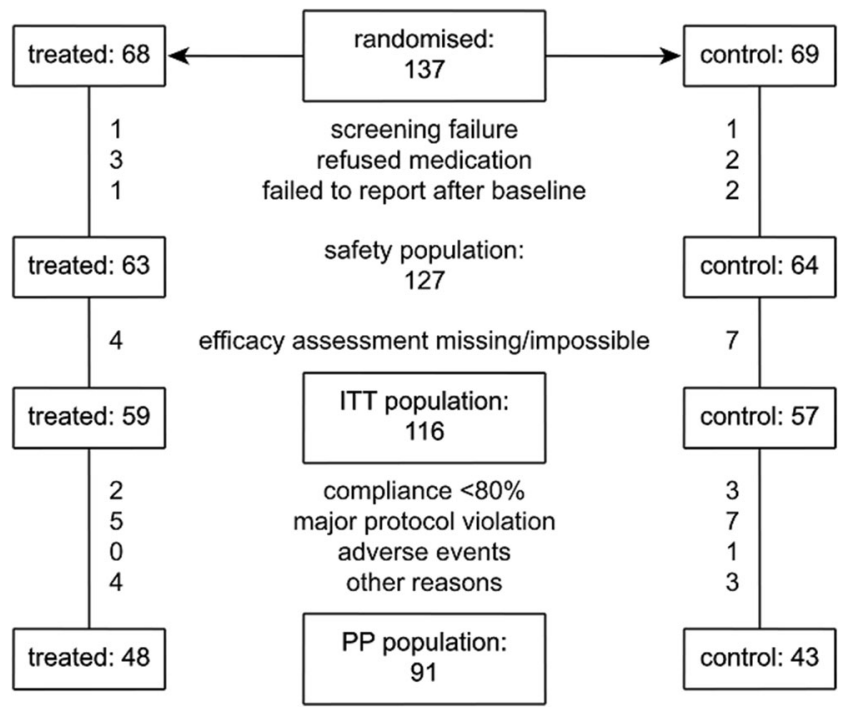

Fig. 3 Patients' dispositions. ITT $=$ intention to treat, $\mathrm{PP}=$ per protocol 
two points on the grading scale. Based on the existing literature, it is estimated that such a decrease could spontaneously occur in approximately $20-30 \%$ of the patients, thus reflecting known fluctuations that exist in the severity of background retinopathy. The study design was consistent with the choice of a two-tailed, chi-square test for significant differences between proportions. An accepted level of significance was $P \leq 0.05$, with a wanted power of $90 \%$. Using a sample size of 56 patients per group, the study would have had a power of $90.2 \%$ to yield statistically significant results under the conditions expressed above. In order to account for non-assessable cases and for randomization in blocks, the sample size was increased to 65 patients per group. Chisquare test was accompanied by a relative risk estimate of the proportion of improved patients in the ITT population. To exclude any effect associated with demography, history, and progress of underlying diabetes, the rate of success was also analyzed using binary multivariable logistic regression analysis. The following were included among the putative predictors: baseline HE severity ( $\leq 4 \mathrm{a} />4 \mathrm{a})$; number of affected eyes; age ( $<60 / \geq 60$ years); sex; body mass index (BMI) $(<25 / \geq 25)$; diabetes duration $(<10 / \geq 10$ years); as well as the changes estimated with the last observation carried forward procedure and coded as decreased vs. unchanged or increased - in blood glucose, Hb1 Ac, total cholesterol, high density lipoprotein (HDL), low density lipoprotein (LDL), and triglycerides (TG). These analyses were also performed on the PP population.

The secondary efficacy endpoints were only analyzed only in the ITT population.

The safety analysis, performed on the safety group, monitored the following: the course of adverse events, laboratory data, vital signs, and changes in physical examination. All analyses were performed using the Statistical Package for the Social Science version 12.0 for Windows (SPSS Inc., Chicago, IL, USA).

\section{Results}

Baseline demographic characteristic

There was no evidence of clinical or statistical differences in demographic profile, history of DM, and general or specific medical history, among the treatment groups (Table 2), with the exception of concomitant medications in use (test group, $86.44 \%$; control group, $70.18 \% ; P=0.0332$ ). In detail, 91 of 116 patients the in ITT population have administered combining drugs and the major differences between treatment groups were in medications for digestive system and central nervous system.

\section{Outcomes}

\section{Hard exudates}

Success, which was defined as an improvement in hard exudates by at least two categories of the severity, was seen in $39.0 \%$ of the affected eyes among the treated patients $(95 \%$ confidence interval [CI], 28-50\%) compared to $19.3 \%$ among control patients (95\% CI, 6-33\%). This difference was statistically significant (chi square test, $P=0.005$; Table 3 ). This yields a number needed to treat of five $(95 \% \mathrm{CI}, 3-16)$ to obtain one success more with the tested treatment, in comparison with the standard of care alone. Figure 4 illustrates two paradigmatic cases recorded under treatment (Fig. 4).

The logistic regression yielded an odds ratio (OR) of 2.790 (95\% CI, 1.155-6.743; $P=0.023$ ) for the effect of treatment once adjustments were made for demographic, prognostic and disease confounders, as described in Table 4. The analysis also confirmed some clinically known effects (Table 4). When both eyes were affected, the chance of success was lower (OR 0.430; $95 \%$ CI, 0.190-0.969; $P=0.042$ ). Increased cholesterol reduced the chances of success (OR 0.311; $95 \% \mathrm{CI}$, $0.103-0.940 ; P=0.039$ ), while increased HDL had an opposite effect (OR 2.458; $95 \%$ CI, 1.045-5.780; $P=0.039$ ).

The PP population yielded almost identical results to the ITT population (Table 3), with a success rate of $38.9 \%$ in treated patients compared to $17.6 \%$ in control patients $(P=$ $0.005)$. In this population the logistic regression analysis (Table 4) confirmed the significant treatment effect (OR $4.062,95 \% \mathrm{CI}, 1.432-11.523 ; P=0.008)$ as well as the favourable effect of decreased cholesterol and increased/ unchanged HDL.

\section{Secondary efficacy variables}

None of the tested secondary efficacy variables (FA, BCVA, IOP, CFT, and CST) yielded statistically significant differences between the treatment groups.

\section{Safety analysis}

Overall, 18 out of the 127 patients in the safety population $(14.17 \%)$ reported 32 adverse events: seven out of 63 patients in the treatment group $(11.11 \%)$ reported 17 reactions; and 11 out of 64 patients in the control group (17.19\%) reported 15 reactions. The proportion of patients with adverse events was not significantly different between treatment groups (chi square, $P=0.3263$ ). One treatment patient and two control patients reported potential treatment-related adverse events, all gastrointestinal in nature. One control patient reported a severe event of angina, which was classified as definitely not associated with the assigned treatment. 
Table 2 Baseline characteristics

\begin{tabular}{|c|c|c|c|c|}
\hline \multicolumn{2}{|l|}{ Variable } & \multirow{2}{*}{$\begin{array}{l}\text { Test }(n=59) \\
29(60.4 \%)\end{array}$} & \multirow{2}{*}{$\begin{array}{l}\text { Control }(n=57) \\
19(39.6 \%)\end{array}$} & \multirow{2}{*}{$\frac{P}{0.084^{*}}$} \\
\hline Gender & women, n (\%) & & & \\
\hline Age (yrs) & mean \pm std & $59.1 \pm 8.7$ & $59.9 \pm 10.6$ & $0.893 \dagger$ \\
\hline BMI $\left(\mathrm{kg} / \mathrm{m}^{2}\right)$ & mean \pm std & $23.78 \pm 2.98$ & $23.91 \pm 2.95$ & $0.827 \dagger$ \\
\hline Diabetes duration (yrs) & mean \pm std & $15.4 \pm 8.7$ & $14.2 \pm 7.5$ & $0.441 \dagger$ \\
\hline History of other diseases & yes, n (\%) & $31(52.5 \%)$ & $29(50.9 \%)$ & $0.858^{*}$ \\
\hline History of retinopathy & yes, n (\%) & $57(96.6 \%)$ & $53(93.0 \%)$ & $0.260 \ddagger$ \\
\hline Previous treatments & yes, n (\%) & $5(8.5 \%)$ & $1(1.8 \%)$ & $0.207 \ddagger$ \\
\hline Concurrent treatment & yes, n (\%) & $51(86.4 \%)$ & $40(70.2 \%)$ & $0.033^{*}$ \\
\hline
\end{tabular}

$\mathrm{BMI}=$ body mass index, $\mathrm{kg}=$ kilogram, $\mathrm{m} 2=$ square meter, $n=$ number of patients, $\mathrm{std}=$ standard deviation, yrs $=$ years

$* \chi 2$-test

$\dagger$ Independent $T$ test

tExact test

There were no statistically or clinically relevant evidence of differences between treatment groups with regards to the course of vital signs and laboratory tests.

\section{Discussion}

Diabetic retinopathy is a microvascular complication that primarily affects capillaries, which results in damage to retinal vascular endothelium, leading to leakage and ischemia. Subsequent visual loss is due to the occurrence of hemorrhages, HE, macular edema, and retinal detachment. There are currently several treatment options available for diabetic retinopathy, but no definitely established pharmacological approach has been defined.

Sulodexide is a highly purified GAG with a high affinity for anti-thrombin III, heparin cofactor II, and vascular endothelium $[6,7,19,20]$. Preliminary observations of patients with diabetic retinopathy that were treated with sulodexide have indicated significant reductions in $\mathrm{HE}$, thus highlighting a potential benefit at the retinal capillary level [14]. Moreover, the incidence and severity of adverse events associated with sulodexide was reported to be no different than those of the placebo group, even at high doses, although mild gastrointestinal upsets were reported $[9,21,22]$.

The DRESS research was designed to assess the effectiveness of sulodexide in the treatment of HE in NPDR in type 1 and type 2 DM patients. Vascular complications of DM are generally accompanied by development of endothelial dysfunction or injury, and in experimental models, this endothelial dysfunction or injury is manifested by an increased number of circulating endothelial cells. In vitro and animal models (rats with streptozotocin-induced diabetes) of endothelial injury/dysfunction have reported that sulodexide was able to repair or prevent the endothelial damage, lower the number of circulating endothelial cells, and improve the endotheliumdependent relaxation of small arteries [23-25]. Recently, it was proved that oral sulodexide administration in patients with type $2 \mathrm{DM}$ enhances the availability of precursors for GAG synthesis, thereby improving the endothelial glycocalyx dimension in sublingual and retinal vascular beds. Sulodexide also helped normalization of systemic vascular permeability and GAG metabolism [7].

Table 3 Proportion of success

\begin{tabular}{|c|c|c|c|c|}
\hline Population & Control n (\%) & Test n (\%) & Total n (\%) & Chi square \\
\hline \multicolumn{5}{|l|}{ ITT } \\
\hline Success & $16(19.3 \%)$ & $32(39.0 \%)$ & $48(29.1 \%)$ & \\
\hline Failure & $67(80.7 \%)$ & $50(61.0 \%)$ & $117(70.9 \%)$ & $7.798 ; P=0.005$ \\
\hline Total eyes & 83 & 82 & 165 & \\
\hline \multicolumn{5}{|l|}{ PP } \\
\hline Success & $12(17.6 \%)$ & $28(38.9 \%)$ & $40(28.6 \%)$ & \\
\hline Failure & $56(82.4 \%)$ & $44(61.1 \%)$ & $100(71.4 \%)$ & $7.732 ; P=0.005$ \\
\hline Total eyes & 68 & 72 & 140 & \\
\hline
\end{tabular}

ITT $=$ intention-to-treat, $n=$ number of eyes, $\mathrm{PP}=$ per-protocol 
Fig. 4 Fundus photographs of two subjects in sulodexide group. a At T0, fundus photograph showed grouped hard exudates graded as $4 b-$. b Hard exudates gradually decreased to grade 3 at T6. c Further diminution of hard exudates attained grade 2 at T12. d Funds photograph of another subject revealed grouped hard exudates of grade $4 \mathrm{~b}$ - at T0. e This patient also showed improvement in hard exudates to grade 4a at T6. f Further improvement continued to reach grade 3 at $\mathrm{T} 12$
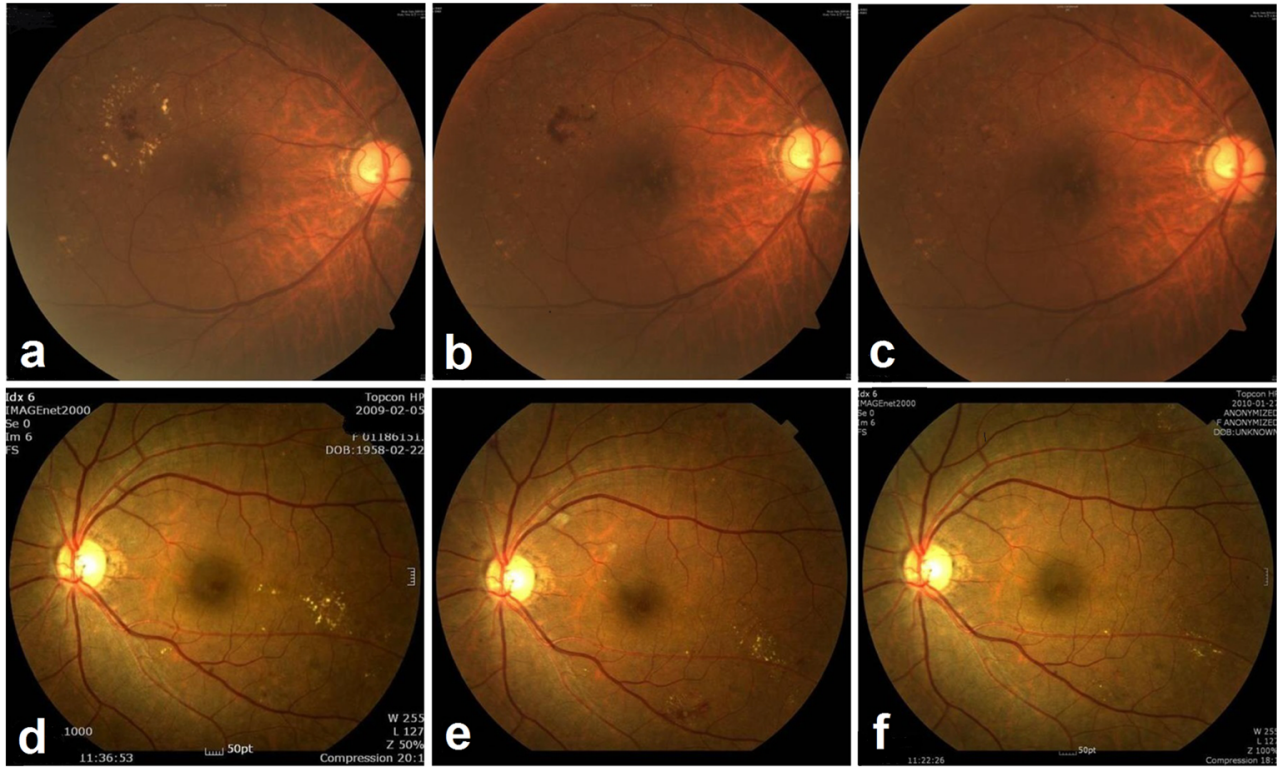

In this double-masked, randomized, multicenter study, efficacy analysis was performed on a total of 165 eyes in the ITT population and a total of 140 eye in the PP population. The primary endpoint of this study, and defined as an improvement

Table 4 Results of the multivariable logistic regression analysis for the outcome "success"

\begin{tabular}{|c|c|c|c|c|}
\hline \multirow[t]{2}{*}{ Variable } & \multicolumn{2}{|l|}{ ITT population } & \multicolumn{2}{|l|}{ PP population } \\
\hline & $\begin{array}{l}\text { OR } \\
{[95 \% \mathrm{CI}]}\end{array}$ & $P$ & $\begin{array}{l}\text { OR } \\
{[95 \% \mathrm{CI}]}\end{array}$ & $P$ \\
\hline $\begin{array}{l}\text { Gender } \\
\text { (male vs. female) }\end{array}$ & $\begin{array}{l}0.840 \\
{[0.379 \text { to } 1.863]}\end{array}$ & 0.669 & $\begin{array}{l}0.915 \\
{[0.385 \text { to } 2.178]}\end{array}$ & 0.841 \\
\hline $\begin{array}{l}\text { Age } \\
(\geq 60 \text { years vs. }<60 \text { years })\end{array}$ & $\begin{array}{l}1.660 \\
{[0.742 \text { to } 3.712]}\end{array}$ & 0.217 & $\begin{array}{l}1.787 \\
{[0.727 \text { to } 4.389]}\end{array}$ & 0.206 \\
\hline $\begin{array}{l}\text { BMI } \\
(\geq 25 \text { vs. }<25)\end{array}$ & $\begin{array}{l}1.557 \\
{[0.661 \text { to } 3.668]}\end{array}$ & 0.311 & $\begin{array}{l}1.612 \\
{[0.597 \text { to } 4.357]}\end{array}$ & 0.346 \\
\hline $\begin{array}{l}\text { Diabetes duration } \\
\text { ( } \geq 10 \text { years vs. }<10 \text { years) }\end{array}$ & $\begin{array}{l}1.101 \\
{[0.415 \text { to } 2.926]}\end{array}$ & 0.846 & $\begin{array}{l}1.372 \\
{[0.462 \text { to } 4.068]}\end{array}$ & 0.569 \\
\hline $\begin{array}{l}\text { Baseline hard exudates severity } \\
(>4 \mathrm{a} \text { vs. } \leq 4 \mathrm{a})\end{array}$ & $\begin{array}{l}2.134 \\
{[0.948 \text { to } 4.805]}\end{array}$ & 0.067 & $\begin{array}{l}1.669 \\
{[0.660 \text { to } 4.222]}\end{array}$ & 0.280 \\
\hline $\begin{array}{l}\text { Affected eyes } \\
\text { (both vs. single) }\end{array}$ & $\begin{array}{l}0.430 \\
{[0.190 \text { to } 0.969]}\end{array}$ & 0.042 & $\begin{array}{l}0.604 \\
{[0.242 \text { to } 1.503]}\end{array}$ & 0.278 \\
\hline $\begin{array}{l}\text { *Glycaemia } \\
\text { (†increased vs. decreased) }\end{array}$ & $\begin{array}{l}0.824 \\
{[0.371 \text { to } 1.833]}\end{array}$ & 0.636 & $\begin{array}{l}0.663 \\
{[0.264 \text { to } 1.664]}\end{array}$ & 0.382 \\
\hline $\begin{array}{l}* \mathrm{Hb} 1 \mathrm{Ac} \\
(† \text { increased vs. decreased) }\end{array}$ & $\begin{array}{l}0.841 \\
{[0.377 \text { to } 1.876]}\end{array}$ & 0.672 & $\begin{array}{l}0.675 \\
{[0.259 \text { to } 1.757]}\end{array}$ & 0.420 \\
\hline $\begin{array}{l}\text { *Cholesterol } \\
\text { (†increased vs. decreased) }\end{array}$ & $\begin{array}{l}0.311 \\
{[0.103 \text { to } 0.940]}\end{array}$ & 0.039 & $\begin{array}{l}0.279 \\
{[0.083 \text { to } 0.934]}\end{array}$ & 0.038 \\
\hline $\begin{array}{l}\text { *HDL } \\
\text { (†increased vs. decreased) }\end{array}$ & $\begin{array}{l}2.458 \\
{[1.045 \text { to } 5.780]}\end{array}$ & 0.039 & $\begin{array}{l}3.092 \\
{[1.160 \text { to } 8.238]}\end{array}$ & 0.024 \\
\hline $\begin{array}{l}\text { *LDL } \\
\text { (†increased vs. decreased) }\end{array}$ & $\begin{array}{l}2.038 \\
{[0.741 \text { to } 5.606]}\end{array}$ & 0.168 & $\begin{array}{l}2.193 \\
{[0.727 \text { to } 6.617]}\end{array}$ & 0.164 \\
\hline $\begin{array}{l}\text { *Triglycerides } \\
\text { (†increased vs. decreased) }\end{array}$ & $\begin{array}{l}1.012 \\
{[0.428 \text { to } 2.394]}\end{array}$ & 0.977 & $\begin{array}{l}1.532 \\
{[0.586 \text { to } 4.002]}\end{array}$ & 0.384 \\
\hline $\begin{array}{l}\text { Treatment } \\
\text { (test vs. control) }\end{array}$ & $\begin{array}{l}2.790 \\
{[1.155 \text { to } 6.743]}\end{array}$ & 0.023 & $\begin{array}{l}4.062 \\
{[1.432 \text { to } 11.523]}\end{array}$ & 0.008 \\
\hline
\end{tabular}

$\mathrm{BMI}=$ body mass index, $\mathrm{CI}=$ confidence interval, $\mathrm{HbAlc}=$ glycosylated hemoglobin, $\mathrm{HDL}=$ high density lipoprotein, $\mathrm{ITT}=$ intention-to-treat, $\mathrm{LDL}=$ low density lipoprotein, $\mathrm{OR}=$ odds ratio, $\mathrm{PP}=$ per-protocol

* Change in the 12-month observation, estimated with the last observation carried forward procedure

$\dagger$ Increased set includes cases of unchanged values 
in HE by two categories of severity, was significantly greater among patients receiving sulodexide compared to the control group, both in the ITT and PP populations. In addition to the significant treatment effect, our study displayed a significantly negative effect of high cholesterol and a significantly positive effect of HDL. Other variables reported to be clinically related to changes in the severity of HE, namely blood glucose, HbAlc, LDL, and TG, were not found to be significant predictors of success or failure in this study. This study also showed a favorable safety profile of sulodexide.

The trial recruited diabetes patients with only mild-tomoderate retinopathy and relatively good vision, and hypothesized that sulodexide could be effective at the early phases of exudation, when permanent damage to the vessel wall has not yet occurred. In the presence of permanent organ damage, other metabolic pathways and new pathologic factors such as vascular endothelial growth factor (VEGF) might become activated, which may not respond to the pharmacodynamics of sulodexide. None the less, further investigation of its use in patients with more severe diabetic retinopathy and/or low vision due to macular edema is required. If the results are positive, sulodexide may act as an adjunctive treatment to laser therapy or anti-VEGF agents, which are the current treatment standard.

Although an improvement in HE was significantly greater in the suldoexide group compared to the control group, about $60 \%$ of patients receiving sulodexide did not react to the treatment. It might be partly due to the low dose of study drug and the limited duration of treatment. This study used the lowest daily dose of sulodexide, because of the safety issue. Another explanation for this result might be the limited effect of sulodexide on vessel wall. Sulodexide is postulated to have its beneficial effect on retinal capillary by partial restoration of GAG content. The vascular leakage, resulting in HE, in a diabetic retinopathy is also caused by some other factors, e.g. loosening of endothelial tight junctions induced by VEGF. The use of sulodexide could have decreased the vascular leakage by supplementing GAGs of capillary basement membrane and correcting altered anionic charge. However, there were still other pathogenic factors increasing vascular permeability and not influenced by sulodexide treatment. These might have resulted in partial response to sulodexide.

One of the limitations of this study is the relatively high proportion of ITT patients, 25 out of 116, who did not complete the study according to protocol (Fig. 3). However, we consider it unlikely that this introduced a substantial bias in the evaluation of the drug effect, since the ITT and PP results were comparable, and the proportion of patients and reason for exclusion were very similar between the two treatment groups.

Another limitation is that the dose of sulodexide used in this study has not been validated for the management of diabetic retinopathy. We selected the $50 \mathrm{mg}$ daily dose, a common regimen used in clinical practice that has also been reported in several published clinical trials, mainly for precautionary reasons given the long duration of treatment (1 year). Other studies in diabetes patients used higher doses (100$400 \mathrm{mg}$ per day); however, the duration of treatment in these cases was significantly shorter (4-6 months) $[9,11,14,16$, 26]. Considering the safety of sulodexide observed in this study, a higher daily dose should be used in any subsequent long-term evaluations of this drug in patients with diabetic retinopathy.

In conclusion, the results of our study indicate that the use of sulodexide, a natural GAG with complex effects on the vascular wall, effected a decrease in macular HE in patients with mild-to-moderate NPDR and the sulodexde treatment group showed significantly greater improvement in HE severity than that shown by the placebo group. However, further and probably larger long-term studies are warranted, possibly with higher dosages, to confirm whether the treatment with sulodexide has a sustained beneficial effect on NPDR.

Acknowledgments The authors thank the DRESS research group served as participating investigators and patients for participating in the study. A complete list of participating investigators can be found in Appendices.

Disclosure statement The authors have no proprietary or commercial interest in any of the materials discussed in this paper. There are no funding bodies for this study.

Financial support None.

Open Access This article is distributed under the terms of the Creative Commons Attribution License which permits any use, distribution, and reproduction in any medium, provided the original author(s) and the source are credited.

\section{References}

1. Aiello LP, Gardner TW, King GL, Blankenship G, Cavallerano JD, Ferris FL 3rd, Klein R (1998) Diabetic retinopathy. Diabetes Care 21: $143-156$

2. Deckert T, Feldt-Rasmussen B, Borch-Johnsen K, Jensen T, KofoedEnevoldsen A (1989) Albuminuria reflects widespread vascular damage. the steno hypothesis. Diabetologia 32:219-226

3. Gambaro G, Skrha J, Ceriello A (1998) Glycosaminoglycan therapy for long-term diabetic complications? Diabetologia 41:975-979

4. Cruickshanks KJ, Ritter LL, Klein R, Moss SE (1993) The association of microalbuminuria with diabetic retinopathy. the wisconsin epidemiologic study of diabetic retinopathy. Ophthalmology 100: 862-867

5. Silvestro L, Lanzarotti E, Marchi E, Gori M, Pescador R, Ferro L, Milani MR, Da Col R, Coppini A (1994) Human pharmacokinetics of glycosaminoglycans using deuterium-labeled and unlabeled substances: evidence for oral absorption. Semin Thromb Hemost 20: 281-292

6. Marchi E, Barbanti M, Milani R, Breccia A, Fini A, Gattavecchia E (1994) Organ glycosaminoglycan distribution after intravenous and oral administration in rats. Semin Thromb Hemost 20:297-300 
7. Broekhuizen LN, Lemkes BA, Mooij HL, Meuwese MC, Verberne H, Holleman F, Schlingemann RO, Nieuwdorp M, Stroes ES, Vink H (2010) Effect of sulodexide on endothelial glycocalyx and vascular permeability in patients with type 2 diabetes mellitus. Diabetologia 53:2646-2655

8. Solini A, Vergnani L, Ricci F, Crepaldi G (1997) Glycosaminoglycans delay the progression of nephropathy in NIDDM. Diabetes Care 20:819-823

9. Gambaro G, Kinalska I, Oksa A, Pont'uch P, Hertlova M, Olsovsky J, Manitius J, Fedele D, Czekalski S, Perusicova J, Skrha J, Taton J, Grzeszczak W, Crepaldi G (2002) Oral sulodexide reduces albuminuria in microalbuminuric and macroalbuminuric type 1 and type 2 diabetic patients: the Di. N.A.S. randomized trial. J Am Soc Nephrol 13:1615-1625

10. Achour A, Kacem M, Dibej K, Skhiri H, Bouraoui S, El May M (2005) One year course of oral sulodexide in the management of diabetic nephropathy. J Nephrol 18:568-574

11. Heerspink HL, Greene T, Lewis JB, Raz I, Rohde RD, Hunsicker LG, Schwartz SL, Aronoff S, Katz MA, Eisner GM, Mersey JH, Wiegmann TB (2008) Effects of sulodexide in patients with type 2 diabetes and persistent albuminuria. Nephrol Dial Transplant 23: 1946-1954

12. Blouza S, Dakhli S, Abid H, Aissaoui M, Ardhaoui I, Ben Abdallah N, Ben Brahim S, Ben Ghorbel I, Ben Salem N, Beji S, Chamakhi S, Derbel A, Derouiche F, Djait F, Doghri T, Fourti Y, Gharbi F, Jellouli K, Jellazi N, Kamoun K, Khedher A, Letaief A, Limam R, Mekaouer A, Miledi R, Nagati K, Naouar M, Sellem S, Tarzi H, Turki S, Zidi B, Achour A (2010) Efficacy of low-dose oral sulodexide in the management of diabetic nephropathy. J Nephrol 23:415-424

13. Turgut F, Bolton WK (2010) Potential new therapeutic agents for diabetic kidney disease. Am J Kidney Dis 55:928-940

14. Rubbi F, Caramazza R, Boccia S, Cozza N, Ghinato U, Gulli R, Menna A, Trainito G (2000) The effects of sulodexide on diabetic retinopathy. Minerva Cardioangiol 48:81-82

15. D'Aloia A, Dati M, Della Corte M, Romano M, Lanza M, Romano A (2001) Assessment of the effectiveness of sulodexide on diabetic patients. Boll Oculistica 80:37-41

16. Lambers Heerspink HJ, Fowler MJ, Volgi J, Reutens AT, Klein I, Herskovits TA, Packham DK, Fraser IR, Schwartz SL, Abaterusso C, Lewis J (2007) Rationale for and study design of the sulodexide trials in type 2 diabetic, hypertensive patients with microalbuminuria or overt nephropathy. Diabet Med 24:1290-1295

17. Early Treatment Diabetic Retinopathy Study Research Group (1991) Grading diabetic retinopathy from stereoscopic color fundus photographs-an extension of the modified airlie house classification. ETDRS report number 10. Ophthalmology 98:786-806

18. Early Treatment Diabetic Retinopathy Study Research Group (1991) Classification of diabetic retinopathy from fluorescein angiograms. ETDRS report number 11. Ophthalmology 98:807-822

19. Buchanan MR, Liao P, Smith LJ, Ofosu FA (1994) Prevention of thrombus formation and growth by antithrombin III and heparin cofactor II-dependent thrombin inhibitors: importance of heparin cofactor II. Thromb Res 74:463-475

20. Borawski J, Dubowski M, Rydzewska-Rosolowska A, Mysliwiec M (2009) Intravenous and oral sulodexide versus coagulation activation markers in humans. Clin Appl Thromb Hemost 15:596-598

21. Coccheri S, Scondotto G, Agnelli G, Aloisi D, Palazzini E, Zamboni V (2002) Randomised, double blind, multicentre, placebo controlled study of sulodexide in the treatment of venous leg ulcers. Thromb Haemost 87:947-952

22. Coccheri S, Scondotto G, Agnelli G, Palazzini E, Zamboni V (2002) Sulodexide in the treatment of intermittent claudication. results of a randomized, double-blind, multicentre, placebo-controlled study. Eur Heart J 23:1057-1065

23. Kristova V, Kriska M, Babal P, Djibril MN, Slamova J, Kurtansky A (2000) Evaluation of endothelium-protective effects of drugs in experimental models of endothelial damage. Physiol Res 49:123-128

24. Kristova V, Liskova S, Sotnikova R, Vojtko R, Kurtansky A (2008) Sulodexide improves endothelial dysfunction in streptozotocininduced diabetes in rats. Physiol Res 57:491-494

25. Kristova V, Kriska M, Vojtko R, Petrova M, Liskova S, Villaris R, Varga Z, Wawruch M (2011) Trends in vascular pharmacology research in the department of pharmacology and clinical pharmacology, faculty of medicine, Comenius University, Bratislava. Interdiscip Toxicol 4:40-46

26. Lewis EJ, Lewis JB, Greene T, Hunsicker LG, Berl T, Pohl MA, de Zeeuw D, Heerspink HL, Rohde RD, Atkins RC, Reutens AT, Packham DK, Raz I (2011) Sulodexide for kidney protection in type 2 diabetes patients with microalbuminuria: a randomized controlled trial. Am J Kidney Dis 58:729-736 